\title{
A PARTICIPAÇÃO POPULAR NA ÚLTIMA ELEIÇÃO PRESIDENCIAL E A DEMOCRACIA BRASILEIRA: FALÁCIA DO ENGAJAMENTO POLÍTICO E CRISE DA REPRESENTATIVIDADE
POPULAR PARTICIPATION IN THE LAST PRESIDENTIAL ELECTION AND BRAZILIAN DEMOCRACY : ENGAGEMENT FALLACY AND REPRESENTATIVE CRISIS

\author{
${ }^{1}$ Priscila Rainato Zhouri \\ ${ }^{2}$ Alice de Siqueira Khouri
}

\section{RESUMO}

Seja por ausência de participação do povo brasileiro na consolidação da República ou, ainda, pela experimentação tardia do fenômeno democrático, a experiência democrática brasileira não se comportou, na prática, com a mesma efusividade que nascera. Os movimentos populares antecessores à eleição presidencial de 2014 pareceram uma retomada do papel ativo na política pelos cidadãos, significando uma aparente mudança na nossa democracia. Os índices de comparecimento às urnas, contudo, diminuíram substancialmente em comparação com as duas últimas eleições presidenciais. O descompasso entre o suposto engajamento político, altamente noticiado pela mídia, e a diminuição do exercício efetivo do poder de escolha pelos cidadãos, evidencia a importância do olhar jurídico e sociológico para a atual situação da democracia no Brasil, assolada por uma possível crise na representatividade e legitimidade do povo brasileiro. Há, portanto, a necessidade de reformar o processo de interação iterativa entre representantes e representados, de forma a estimular a participação política e a cultura cívica da população.

Palavras-chave: Participação popular, Democracia, Representatividade, Republicanismo, Eleição presidencial, Reforma

\footnotetext{
${ }^{1}$ Mestranda em Direito pela Pontifícia Universidade Católica de Minas Gerais (PUC Minas), Minas Gerais (Brasil). E-mail: priscilazhouri@yahoo.com

${ }^{2}$ Mestranda em Direito pela Pontifícia Universidade Católica de Minas Gerais (PUC Minas), Minas Gerais (Brasil). E-mail: a.khouri@rolimvlc.com
} 


\begin{abstract}
Either by lack of participation of the Brazilian people in the consolidation of the Republic, or even the late trial of the democratic phenomenon, the Brazilian democratic experience did not behave in practice with the same effusiveness with which it was born. Popular movements predecessors to the presidential election of 2014 seemed a resumption of an active role in politics by citizens, meaning an apparent change in our democracy. The turnout rates to the polls, however, decreased substantially compared to the last two presidential elections. The gap between the supposed political engagement, highly publicized by the media, and the decrease in the effective exercise of the vote by citizens, highlights the importance of the legal and sociological look at the current state of democracy in Brazil, beset by a possible crisis in representation and legitimacy of the Brazilian people. There is therefore the need to reform the process of iterative interaction between representatives and represented, in order to stimulate political participation and civic culture of the population.
\end{abstract}

Keywords: Popular participation, Democracy, Representation, Republicanism, Brazilian presidential election, Reform 


\section{INTRODUÇÃO}

Com a falência do regime monárquico e a queda do Império em 1889, foi proclamada a República dos Estados Unidos do Brasil e, neste momento, pode-se dizer que, bem superficialmente, estava plantada a semente da democracia. Ainda que de forma incipiente, a queda do regime imperial e a desconstituição da monarquia, resquício absolutista, marcaram o início de uma nova era na qual o governo não representaria mais hereditariedade ou vontade divina.

A res publica veio, portanto, em teoria, inaugurar a construção do Estado para o povo, o que mais tarde se revelaria somente possível mediante reconhecimento deste como sujeito ativo na vida pública. Contudo, os anais da história demonstram que a realidade vivenciada em um primeiro momento não foi a de efetivação do verdadeiro intuito republicano, posto que não havia, ainda, qualquer pretensão democrática de inclusão do povo na participação da política.

Ao contrário, a experimentação da república pelo Brasil representou tão somente um subterfúgio à vontade das elites que dominavam o cenário político e as relações de poder, significando à época, apenas uma mudança na dinâmica de exercício do poder, sendo a figura do monarca substituída pelos líderes da elite econômica.

Aristides Lobo, na carta sobre o episódio de 15 de novembro de 1889, assim narra o momento de ruptura do regime imperial:

Por ora, a cor do governo é puramente militar e deverá ser assim. O fato foi deles, deles só porque a colaboração do elemento civil foi quase nula. $\mathrm{O}$ povo assistiu àquilo tudo bestializado, atônito, surpreso, sem conhecer o que significava. Muitos acreditaram seriamente estar vendo uma parada!

Ainda que alguns digam que a inauguração da República não possuiu qualquer traço democrático $^{1}$, entende-se, em uma concepção mais otimista, que fora um importante marco

\footnotetext{
${ }^{1}$ Não se pode confundir 'república' e 'democracia', e nas palavras de Kant: "Para que não se confunda a Constituição republicana com a democrática (como é comum acontecer), deve-se notar o seguinte. As formas de um Estado podem ser distinguidas segundo as pessoas que possuem o poder soberano, ou segundo o modo de exercício do poder sobre o povo por parte do soberano, seja ele quem for. A primeira distinção diz respeito à forma de domínio (...). Existem apenas três modalidades possíveis: a autocracia, na qual um possui o poder soberano; a aristocracia, na qual alguns se associam para juntos possuírem tal poder; ou a democracia, na qual todos aqueles que constituem a sociedade possuem o poder soberano. Podem ser caracterizadas, respectivamente, como o poder de um monarca, da nobreza ou do povo. A segunda distinção diz respeito à forma de governo, ou seja, à maneira pela qual o Estado utiliza o seu poder. Essa maneira é baseada na Constituição, que é o ato da vontade geral através do qual a multiplicidade de pessoas torna-se uma nação. Desse ponto de vista o governo ou é republicano ou é despótico. O republicanismo é o princípio de organização do Estado que
} 
histórico, significando uma mudança de pensamento da relação Estado - Povo e este, ainda que não ativo, foi concebido, em teoria, como destinatário da ação estatal, sendo reconhecido pela primeira vez, de certa forma, na construção do Estado brasileiro.

A grande conquista, contudo, foi ao final da República Velha (1889-1930), com o primeiro governo de Getúlio Vargas e o início de um período pretensamente democrático. Ainda que logo interrompido pelos golpes militares e a ascensão do governo ditatorial, nascia a ideia de democracia e o reconhecimento de um povo não só destinatário, mas também participante. Com a disseminação da ideia democrática, portanto, houve a inversão dos papéis na política e a assunção pelo povo do papel participativo ao invés de mero instrumento de joguete das elites. Nascia, neste momento histórico, o reconhecimento da importância da participação popular na tomada de decisões e consolidação da política.

Contudo, seja por ausência de participação do povo na consolidação da República ou, ainda, pela experimentação tardia do fenômeno democrático, fato é que a experiência brasileira não se comportou, na prática, com a mesma efusividade com que nascera, tendo a participação popular se esvaído no tempo e dissipado aos poucos.

Surge, nessa realidade fática, a importância de o Direito e as Ciências Sociais voltaremse para a análise do comportamento brasileiro e a legitimidade da pretensa democracia vivenciada e incluir em seus estudos a preocupação não só com o diagnóstico da conjuntura nacional, mas também com os efeitos de uma participação inefetiva, distante do que o ideal democrático republicano de fato consiste.

Nesse contexto, reconhecendo o presente trabalho a importância da referida análise, pretende-se avaliar se, em momentos de grande comoção popular como os experimentados em 2014 antecedentes à última eleição presidencial - o que, em tese denotaria maior maturidade democrática e participação - de fato representa a retomada do povo, de seu papel ativo conferido pela Constituição de 1988.

Para a construção da referida análise, utilizamos como base teórica as lições de juristas e historiadores nacionais, em paralelo com a doutrina republicanista norte americana trazida por Bruce Ackerman. Com contribuições bem distintas, as teorias abordadas

estabelece a separação entre o poder executivo (o governo) e o legislativo; o despotismo é o da execução autônoma pelo Estado das leis que ele mesmo decretou. Assim, num despotismo, a vontade política é administrada pelo governante como se fossa a sua própria vontade. Dentre as três modalidades de Estado, a da democracia, propriamente falando, é necessariamente um despotismo, porque ela estabelece um poder executivo no qual 'todos' decidem por - ou mesmo contra - um que não concorda; ou seja, 'todos', que não são exatamente todos, decidem, e isto é uma contradição da vontade geral, consigo mesma e com a liberdade (KANT, 1990, pp. 78-9). 
ofereceram substrato conceitual indispensável para a compreensão consistente do comportamento popular democrático no Brasil e análise crítica da conjuntura atual.

\section{APRESENTAÇÃO DO CASO EM ANÁLISE: ÍNDICE COMPARATIVO DA PARTICIPAÇÃO POPULAR BRASILEIRA NAS DUAS ÚLTIMAS ELEIÇÕES PRESIDENCIAIS}

A última eleição presidencial, em outubro de 2014, foi antecedida por uma série de movimentos populares não organizados, alguns marcados por certa agressividade, outros nem tanto.

Delineadas por diferenças ideológicas e antagônicas entre os partidos concorrentes, e estas, por sua vez, acirradas pela mídia, as manifestações populares trouxeram à tona a dúvida acerca do comprometimento popular com a democracia e a vida política. O país, até então adormecido "em berço esplêndido", pareceu despertar para a disputa política como há tempos não fazia, e uma reflexão jurídica acerca do comportamento da sociedade ganha espaço: a invasão do espaço público pelas acaloradas discussões políticas seria efetivamente o amadurecimento democrático tardio do povo? Estivemos diante da retomada do papel ativo conferido pela democracia à população?

À parte de especulações político partidárias exaustivamente tratadas pela mídia jornalística e em publicações especializadas, fato é que, empiricamente, o resultado do primeiro turno das eleições de 2014 confirma a tendência de queda no comparecimento de eleitores às urnas, conforme dados registrados desde 2006 (BRASIL, TSE, 2010) pelo Tribunal Superior Eleitoral (TSE).

Considerando ser a população no Brasil em 2014 de 201.032.714 habitantes e o eleitorado apto de 142.822.046 (aproximadamente 71,04\%), conforme se infere da análise dos dados relativos à última eleição presidencial (2014), apenas 80,61\% dos eleitores aptos compareceram às urnas para exercer o seu direito político. Dessa forma, 19,39\% do eleitores, ou seja, mais de 27,6 milhões de pessoas, não compareceram às urnas no primeiro turno.

Comparativamente, em 2010, a população brasileira representava 193.252.604 habitantes, com eleitorado apto de 135.804.433 (aproximadamente 70,27\%), e compareceram às urnas para votar no primeiro turno $81,79 \%$, sendo ausente a porcentagem $18,21 \%$, o que 
equivale, aproximadamente, a 24,7 milhões de pessoas. Ou seja, 2,9 milhões de pessoas a menos que em 2014.

Da simples comparação empírica dos dados, deflui-se que, em 2010, mais brasileiros exerceram seu direito de voto e compareceram às urnas na eleição presidencial para escolher o seu representante.

A tendência de aumento das abstenções retratada no comparativo das eleições presidenciais de 2010 e 2014 pode ser reafirmada ao observarmos os dados da eleição de 2006, na qual o percentual dos que não votaram representou $16,75 \%$, o que equivale aproxidamente $^{2}$ a 21,09 milhões de pessoas. Ou seja: 4,61 milhões de ausentes a menos que em 2010 e, 7,51 milhões a menos de eleitores que não votaram em 2014.

Referido comportamento absenteísta ganha contornos ainda mais acentuados ao observamos o percentual de comparecimento às urnas no segundo turno das eleições. Frise-se, neste ponto, que as manifestações populares no interregno do primeiro e segundo turnos da eleição presidencial se intensificaram. Em 2006, 18,99\% dos aptos a votar não foram às urnas, percentual que subiu para 21,55\% em 2010 e manteve-se relativamente estável em 2014, com aproximadamente $21,0 \%$ de eleitores aptos que não votaram no segundo turno da eleição.

Ao confrontarmos os dados acima expostos com o cenário conturbado de manifestações populares de insatisfação com os representantes políticos concorrentes à presidência da República, percebe-se, sem esforço hercúleo, um contrassenso. Ao contrário do esperado diante do suposto civismo exaltado nos inúmeros movimentos pelas opostas bandeiras partidárias, o número de brasileiros que efetivamente exerceram o seu direito de voto diminuiu significativamente em comparação com as duas últimas eleições presidenciais (2006 e 2010).

A contradição acima evidenciada atrai a importância de revisitar conceitos como representatividade, republicanismo e democracia na doutrina, de forma a verificar o grau de absorção do significado prático inerente a esses conceitos pela sociedade brasileira.

\section{A TEORIA DE BRUCE ACKERMAN: NÍVEIS DE PARTICIPAÇÃo POLÍTICA DO CIDADÃO}

\footnotetext{
${ }^{2}$ Número obtido considerando o eleitorado apto em 2006 como de 125.913 .479 habitantes. Dados, uma vez mais, retirados do arquivo "Informações e dados estatísticos sobre eleições 2010" e do TSE.
} 
Bruce Ackerman desenvolve sua teoria do constitucionalismo criticando a teoria monista de Alexander Bickel (1962), a qual traz à tona a dificuldade contramajoritária espelhada pelo controle de constitucionalidade da Suprema Corte norte-americana. Referida tensão contramajoritária existiria na medida em que considera os representantes do povo no parlamento como manifestantes da vontade popular.

Em contrapartida, Ackerman (1991) desenvolve a noção dualista da democracia na qual a vontade popular não coincide com a vontade manifestada pelos representantes eleitos pelo povo. Segundo sua teoria, o processo democrático norte-americano se realizaria ora pelo povo diretamente, ora por seus representantes eleitos. Para o autor, o "povo" apenas se apresenta ou se manifesta em especiais circunstâncias históricas, marcadamente por aquelas relacionadas ao grande engajamento dos indivíduos em torno de questões de interesse público. Apenas nestes momentos, o Direito coincidiria com a vontade popular, concretizando-se, assim, o princípio republicano de autogoverno.

A política ordinária, então, seria aquela realizada no cotidiano, voltada apenas a satisfação de interesses particulares, ao passo que a política constitucional, ou seja, aquela derivada de um grande comprometimento popular, apenas extraordinariamente ocorreria, ainda que ambas derivassem da vontade popular.

Nos períodos de política ordinária, os cidadãos buscariam a realização de interesses meramente individuais - conceito de cidadão privado para o autor - pautados em uma política liberal. Em contrapartida, em excepcionais momentos de política republicana, haveria o envolvimento popular no debate público acerca do bem comum e dos interesses sociais.

Ackerman propõe a junção do paradigma liberal-republicano como forma de compreender a sociedade americana e superar a tensão contramajoritária de Bickel. Diante disto, conclui que os representantes políticos não coincidem com o "povo" e, sendo assim, qualquer controle jurisdicional seria efetivo e salutar, na medida em que protegeria o próprio "povo" contra incursões do legislativo em momentos de apatia política, na tentativa de romper com as decisões acerca do interesse público tomadas pelo próprio "povo" em momentos de intenso engajamento popular.

No que pese a teoria republicana desenvolvida por Bruce Ackerman em seu livro We The People, voltada para o contexto norte americano brevemente aqui narrado, para o caso em 
análise a contribuição do autor possui especial relevância no que concerne à análise comportamental do cidadão, considerando os níveis de sua participação na vida política e no exercício da democracia.

Para o autor, a sociedade civil é híbrida e composta por indivíduos que exercitam sua cidadania em níveis diferentes, cidadãos que diferem entre si por seu grau de participação na vida cívica, em cumprimento gradativo do exercício democrático. Nesse contexto, Ackerman conceitua, de forma esparsa e dando ênfase às características de cada um, os cidadãos privados, perfeitos privatistas e cidadãos públicos (ACKERMAN, 1991).

Os primeiros são os que mais interessam ao caso analisado, em conexão a ser desenvolvida em tópico posterior, contudo, cumpre esclarecer que a teoria do autor norte americano define como perfeitos privatistas aqueles que se preocupam única e exclusivamente com seus interesses privados, não participando da vida política de forma alguma. Em outro extremo, estariam os cidadãos públicos, dedicados à vida pública e ativos politicamente, encontrando sua virtude na participação cívica.

Equacionando os extremos da gradação de participação política construída pelo autor, estão os cidadãos privados, aqueles que exercem mínima e superficialmente o seu papel democrático, preocupando-se ordinariamente com suas atividades diárias e seus interesses particulares, fazendo com que essa participação cívica ocorra apenas na medida necessária para o alcance de seus objetivos e interesses particulares.

Para Ackerman, esse tipo de cidadão seria o mais comum, constituindo a maior parte da sociedade. Nas palavras do autor:

\begin{abstract}
I shall assume a population composed principally (but not exclusively) of private citizens - Americans who recognize the meaningfulness of the Pubian enterprize, but content themselves with conduct they themselves recognize as insuficientelly informed. Public-regarding, and politically active to fulfill their own aspirations as private citizens. ${ }^{3}$ (ACKERMAN, 1991, p. 243)
\end{abstract}

O cidadão privado, na concepção de Ackerman, ao exercer minimamente o seu papel na democracia, basicamente através de seu voto na escolha dos dirigentes políticos, não o faz de forma consciente e muito menos crítica, cumprindo seu papel de forma medíocre e quase autômata. Para o autor, a participação do cidadão por meio desse voto sem, contudo, a referida análise crítica, seria mero "soft vote", o que não é desconsiderado totalmente pelo

\footnotetext{
${ }^{3}$ Tradução nossa: "Eu devo assumir que a população é composta majoritariamente (mas não exclusivamente) de cidadãos privados -- Americanos que reconhecem a ausência de significado da vida pública/cívica mas se contentam com a conduta que eles mesmos reconhecem como insuficiente de informação, no que tange a vida pública e a participação política para preencher suas próprias aspirações enquanto cidadãos privados.”
} 
autor, mas, reduz-se à manifestação das impressões do eleitor sobre os candidatos, considerando parâmetros de prosperidade e vida pregressa (ACKERMAN, 1991, p. 241).

A divisão teórica de Ackerman da sociedade norte americana em níveis de participação política pelos cidadãos pode auxiliar na compreensão da sociedade brasileira, na medida em que, aqui também, existem graus distintos de comprometimento democrático.

No caso em análise, por exemplo, os movimentos populares antecessores à eleição presidencial de 2014, à primeira vista, seriam compostos por cidadãos públicos na classificação de Ackerman, engajados com a vida cívica e de virtude republicana.

Contudo, a análise dos dados empíricos apresentados no tópico anterior - da qual se conclui que, apesar da comoção política, menos brasileiros exerceram o seu direito e dever de voto - nos leva a crer que os movimentos políticos foram compostos por cidadãos privados ou, até mesmo, por perfeitos privatistas. Isso porque, apesar de toda a panaceia em torno dos candidatos e respectivos partidos políticos, a sociedade brasileira efetivou o seu poder de escolha em menor grau do que das eleições anteriores.

A teoria de Ackerman é também relevante para análise do caso brasileiro no que tange à contribuição do autor sobre o papel da mídia para formação do conhecimento do cidadão votante. Para o autor, a mídia é instrumento importante na formação da consciência política do cidadão privado e, consequentemente, direcionador do soft vote.

Nesse sentido, os canais de mídia se comportam como fornecedores de informações e veiculação de notícias e dados influenciados pelos políticos. Explica o autor que:

\begin{abstract}
Newspapers and television have little incentive to monitor politician/statesmen on an ongoing, issue-by-issue, bases. Such reports will overwhelm the informationprocessing capacities of the private citizenry that constitutes the mass audience. What this public wants is "news": bits and pieces of current events that require little in the way of unfamiliar background. And yet, given the prevailing passivity of the private citizenry, the mass media provide an essencial mechanism by wich would-be representatives can reach out, however superficially to the bulk of there constituence. If "news" is what they want, news is what politician/statesmen will give them. This leads to a number of familiar distortions (...)Mass midia reward the most superficial kind sloganeering-for it is only such stuff that will be assimilable within the audience's exceedingly modest attention span. The slogans, in turn, will be of two kinds. Most obviously, the private citizenry will receive a steady diet of political banalities inherited from the past - for these slogans, are sufficiently familiar so as not to require elaborate explanation. ${ }^{4}$ (ACKERMAN, 1991, p. 249)
\end{abstract}

\footnotetext{
${ }^{4}$ Tradução nossa: “Jornais e televisão têm pouco incentivo para monitorar políticos/estadistas em um processo em andamento. As notícias irão esgotar as capacidades de processamento de informação dos cidadãos particulares, que constituem o público de massa. O que esse público quer é "notícia": pedaços de eventos atuais que exigem pouco em termos de conhecimento. No entanto, dada a passividade predominante dos cidadãos privados, os meios de comunicação constituem um mecanismo essencial pelo qual os futuros representantes podem alcançar esses cidadãos privados, ainda que superficialmente. Se "notícia" é o que eles querem, é o que os
} 
Tais cidadãos privados, apesar de manipulados em grande parte do tempo pela mídia e influenciados pelas notícias e informações superficiais que recebem em alguns momentos, se transformam em cidadãos ativos politicamente, exercendo o verdadeiro viés democrático de sua cidadania em um momento específico:

\begin{abstract}
Nonetheless, during periods of successful constitutional politics, there is an important difference in their political conversations, actions, attitudes. Their questions become more urgent, their conversations more energetic, their actions move beyond the ballot box to include money contributions, petitions, marches - all to express the fact that they now have a considered judgment that they want there would-be governors to recognize. If italics will do the trick, private citizens become private citizens. If jargon is any better, distinguishing between passive and active citizens will serve, so long, as it is firmly recalled that even the passive citizen is not a perfect privatist, nore is the active one a public citizen - we are distinguishing between shades of grey ${ }^{5}$. (ACKERMAN, 1991, p. 243)
\end{abstract}

Importante destacar que na obra de Ackerman a sociedade em análise é a norte americana, com 227 anos de democracia efetiva e onde o voto é facultativo. Nessa sociedade, a mídia possui função direcionadora do voto e maximizadora do comprometimento popular, gerando, no pior dos cenários, o soft vote criticado pelo autor.

No Brasil, onde a democracia é incipiente e o voto obrigatório, no melhor dos cenários a participação popular, manipulada pela mídia, se equivaleria ao soft vote. No entanto, a realidade democrática brasileira deixa muito a desejar, na medida em que a tendência tem sido o aumento do número de eleitores que não comparecem às urnas, não exercendo, sequer, o soft vote.

No que tange aos movimentos populares aqui tratados, a mídia brasileira funcionou como estimulador da panaceia política, transvestida de participação popular, sem qualquer comprometimento efetivo com a consistência da informação repassada ao eleitor, o que pode

políticos/estadistas lhes dará. Isto leva a uma série de distorções familiares (...) A mídia de massa recompensa o tipo mais superficial de slogan, pois é somente tal material que será assimilável dentro do excessivamente modesto tempo de atenção do público. Os slogans, por sua vez, serão de dois tipos. Obviamente, o cidadão privado receberá uma dieta constante de banalidades políticas herdadas do passado - porque estes slogans são suficientemente familiares, não exigindo explicação elaborada."

${ }^{5}$ Tradução nossa: "No entanto, durante os períodos de política constitucional de sucesso, há uma diferença importante em suas (cidadãos privados) conversas políticas, ações e atitudes. Suas perguntas se tornam mais urgentes, suas conversas mais enérgicas, as suas ações vão além das urnas, incluindo contribuições de dinheiro,

petições, marchas - tudo para expressar o fato de que eles agora têm um juízo considerável que eles querem que seus futuros representantes reconheçam. Se itálico pode representar o que pretendo dizer, cidadãos privados se tornam cidadãos privados. Se o uso de jargão é melhor, a distinção entre os cidadãos passivos e ativos será suficiente enquanto nos lembrarmos que mesmo o cidadão passivo não é um privatista perfeito, e nem tampouco o ativo, um cidadão público - estamos distinguindo entre tons de cinza". 
ser verificado a partir do conteúdo das notícias veiculadas à época em conjunto com o aumento do não comparecimento às urnas.

\section{FALÁCIA DA PARTICIPAÇÃO POPULAR OU CRISE NA REPRESENTATIVIDADE BRASILEIRA?}

Os movimentos populares antecessores à eleição, objeto de análise desse artigo, como dito, poderiam ser vistos como forma de mobilização política. Contudo, a análise dos dados empíricos mostra que não houve um efeito produtivo concreto, na medida em que a tendência de aumento do número de eleitores brasileiros que não comparecem às urnas foi confirmada e acentuada em 2014.

No mínimo irônico o fato de que a comoção popular noticiada, como nunca antes vista, não foi capaz de reverter a cenário de apatia política na sociedade brasileira, posto que não foi rompida a tendência decrescente de participação efetiva dos eleitores, na escolha de seus representantes. Afinal, o voto é o primeiro passo do engajamento do cidadão na tomada de decisões na esfera pública.

Para MANGABEIRA UNGER (1999), a mobilização política precisa do respaldo e comprometimento das instituições com a democracia efetiva, as quais devem servir de catalisadores da participação popular:

\footnotetext{
Uma elevação sustentada do nível de mobilização política é necessária para a aceleração do experimentalismo democrático em todos os campos da vida social. $\mathrm{O}$ nível de mobilização política não é um fato natural na vida de uma sociedade ou uma cultura; é, em grande parte, um artefato, sensível às mudanças nas regras e nos instrumentos da política. Entre essas mudanças estão: financiamento público de campanhas políticas; expansão do livre acesso aos meios de comunicação para os partidos políticos e movimentos sociais; multiplicação das formas de propriedade dos meios de comunicação; normas de votação obrigatória; e mudanças no regime eleitoral. Um sistema de listas fechadas e de representação proporcional é geralmente mais eficiente para reforçar os partidos políticos como agentes de propostas estruturais. Entretanto, a adoção temporária de eleições majoritárias pode, em alguns países, ajudar a reativar um sistema partidário enrijecido e a revelar coalizões progressistas e conservadoras subjacentes. Uma política de reiterada mudança estrutural é necessariamente uma política de alta energia. Para que a alta energia sobreviva aos surtos de entusiasmo coletivo tem de encontrar sustentação em instituições propícias à ascensão do engajamento político popular. Para que a alta energia exerça um efeito produtivo duradouro deve deixar seu trabalho inscrito na ordem institucional e criativa da sociedade. (MANGABEIRA UNGER, 1999, p. 208/9).
} 
Verifica-se que os movimentos populares de 2013/2014 possuíam bandeiras desconectadas da ideologia de cada partido, muito mais atreladas à caricatura dos candidatos do que efetivamente às propostas de governo, tais como medidas sócio econômicas e políticas públicas internas.

Ao contrário, por não ter nenhuma conexão com a função desempenhada pelas instituições e, nenhum respaldo verdadeiramente político por trás da máquina pública, os movimentos populares não exerceram o viés democrático essencial: interação entre representantes e representados, onde os representados detêm o poder de escolha dos seus representantes e, ao efetivá-lo, o poder/dever de exigir o cumprimento das propostas pelas quais foram eleitos.

Surge, nessa diapasão, a importância de ressignificação da representação democrática. O que seria, de fato, uma relação de representação democrática efetiva? Necessariamente aquela respaldada pelas instituições que a cercam e não dependente das incursões da mídia. Na medida em que instituições são efetivamente democráticas, há terreno profícuo para a relação entre representantes e representados, posto que o acompanhamento e o monitoramento por parte destes se dá de forma natural. Como bem pontuado por ANASTASIA e NUNES (2007):

\begin{abstract}
A ampliação e o aperfeiçoamento da representação democrática remetem ao desafio de transformar a democracia em um conjunto de interações iterativas entre representantes e representados, desenvolvidas em um contexto decisório contínuo e institucionalizado. Como fazer? Transformando as Casas Legislativas em "cidades mágicas" (Fishkin,1995), ou seja, locais de deliberação política que permitam e incentivem a interação entre representação e participação políticas, que facultem aos cidadãos a vocalização continuada de suas preferências perante os legisladores e que lhes garantam o acompanhamento e o monitoramento permanente dos movimentos de seus representantes. (ANASTASIA e NUNES, 2007, p. 18)
\end{abstract}

Nesse sentido, com o fortalecimento da relação de representação democrática, o que só parece possível mediante democratização das instituições, diminui-se a insatisfação efusiva meramente superficial e, assim, eleições se tornam processo natural de escolha racional entre as propostas dos candidatos e não palco para discussões egológicas centrífugas da questão principal: construção da política pelos cidadãos através do seu poder de escolha. 


\section{CONSIDERAÇÕES FINAIS}

Ao longo do presente artigo foram visitados conceitos como republicanismo, democracia e representatividade, os quais apresentam o mesmo denominador comum: participação do povo na tomada de decisões, posto que sujeito ativo na política e destinatário do governo. Em todos esses conceitos, portanto, a participação popular é fundamental para sua efetivação e concretude, funcionando como medidores da eficácia prática dos direitos políticos garantidos constitucionalmente em qualquer ordem que se proclame democrática e republicana.

Os movimentos populares vinculados à última eleição presidencial no Brasil (2014) trouxeram à tona a sensação de suposto engajamento político de uma sociedade até então, apática, avessa à política e inerte. Noticiadas pelos jornais e mídia de todo o mundo, as manifestações marcaram a cultura política daquele ano e sinalizaram uma tendência da população de retomada do seu papel ativo na vida pública.

Com o advento da eleição presidencial, contudo, verificou-se que a expectativa de efetiva participação da sociedade não se concretizou, na medida em que foi perpetuada e acentuada a tendência de aumento do número de eleitores aptos que não compareceram às urnas. O número de brasileiros que efetivamente exerceram o seu direito político, consagrado pela democracia de escolha do dirigente executivo nacional, diminuiu substancialmente em comparação com as duas últimas eleições presidenciais. A estatística, portanto, evidenciou que as manifestações populares não passaram de uma panaceia transvestida de participação política.

Com o auxílio da teoria norte americana de Bruce Ackerman, é possível enxergar a sociedade brasileira composta por cidadãos com níveis diferentes de engajamento político. Enquanto uns poucos têm na virtude cívica sua essência, outros apenas participam da vida pública quando está em jogo algo que particularmente lhes interessa. Há, ainda, aqueles totalmente apáticos à esfera pública, sem qualquer participação na política.

Os movimentos populares antecedentes à eleição de 2014 pareceram, em um primeiro momento, serem integrados por cidadãos engajados e preocupados com a vida pública e a tomada de decisões na esfera política. Contudo, considerando a decrescente participação dos eleitores na escolha do presidente da República, vê-se que, em verdade, a 
sociedade brasileira permanece distante do ideal democrático de participação efetiva e consciente do cidadão na política.

Como bem destacado há anos por ANASTASIA e NUNES (2007), é ainda frágil, senão inexistente, a interação iterativa entre representantes e representados, vínculo essencial na ordem democrática para a consolidação da sua ordem dialógica. Na medida em que os movimentos analisados não foram fomentados por debates ideológicos fundamentados, ou sequer respaldados pelas instituições, vê-se que de fato, não possuíram qualquer efeito ou mudança prática na incipiente e frágil democracia brasileira.

As manifestações de 2013/2014 representaram, em verdade, uma insatisfação popular generalizada com a política, denotando um crescente afastamento da população em relação às instituições do Estado Democrático de Direito e um verdadeiro déficit de representatividade. Serviram, por um lado, para demonstrar o referido déficit, ante a completa ausência de direcionamento capaz de trazer uma atuação pontual e informada do cidadão na efetivação de seus direitos políticos garantidos constitucionalmente, não conseguindo influenciar a agenda pública do parlamento.

O presente e crescente afastamento entre cidadãos e instâncias de decisão, fomentador da crise da democracia, apresentar-se como verdadeira realidade, espelhada, especialmente, no que tange o presente trabalho, no crescente nível de abstenção às urnas. Como salientado por MARIÁ BROCHADO (2006), necessário o entendimento por parte dos cidadãos que as autoridades da esfera pública representam o Estado, o qual é fiscalizado, necessariamente, pelos cidadãos.

Desde a implementação do Estado de Direito, a versão indireta da democracia ocupou a centralidade do discurso político e monopolizou a configuração dos sistemas democráticos. A crise da representatividade não é tema novo e encontra-se fundada na quebra da confiança e no descrédito da capacidade das instituições e dos agentes políticos de agirem de forma funcionalmente adequada.

É necessário criar na população um sentimento de inserção diante da coisa pública e da confiança nas instituições democráticas, que seja racionalmente fundamentada, e conduza a um aumento na participação efetiva na tomada de decisões nas esferas do governo, de forma a, efetivamente, influenciar a agenda pública.

Falar em democracia implica, exatamente, em falar de participação. Conforme definição de BOBBIO (1988, p. 13) democracia é “um conjunto de regras processuais no que 
diz respeito à formação das decisões coletivas, prevendo e facilitando a participação mais ampla possível dos interessados."

Verificou-se, portanto, que a nossa República, constituída às avessas do povo, com o desenvolvimento paulatino de um ideal democrático, ainda é incipiente, na medida em que não conseguiu ganhar espaço de discussão madura e informada no seio da sociedade brasileira, representando muito mais uma obrigação do que, verdadeiramente, um direito. Como ilustram os dados do TSE analisados, referentes à última eleição, o "gigante", que supostamente acordou no seio das manifestações populares, no momento de materializar o seu "brado retumbante" voltou a dormir "deitado eternamente em berço esplêndido".

\section{REFERÊNCIAS BIBLIOGRÁFICAS:}


ACKERMAN, Bruce. We the People Foundations. Cambridge/MA, Harvard University Press: 1991, p. 369.

ALMOND, G.; VERBAS, S. The civic culture: political attitudes and democracy in five nations. Newbury Park; Londres; Nova Deli: Sage,1989.

ANASTASIA, Fátima e NUNES, Felipe. A Reforma da Representação. In AVRITZER, Leonardo e ANASTASIA, Fátima, orgs. Reforma Política no Brasil. Belo Horizonte: UFMG, 2007.

BICKEL, Alexander. The Least Dangerous Branch - The Supreme Court at the Bar of Politics. New York: Bobbs-Merril Company, 1962.

BOBBIO, Norberto. O futuro da democracia: uma defesa das regras do jogo. Tradução de Miguel Serras Pereira. Lisboa: Dom Quixote, 1988.

BRASIL. Constituição (1988). Constituição da República Federativa do Brasil, 1988. Brasília: Senado Federal, 1988. Disponível em:

<http://www.planalto.gov.br/ccivil_03/constituicao/constituicao.htm>. Acesso em: 12 ago. 2015.

Brasil. Senado Federal. Disponível em:

http://www12.senado.leg.br/noticias/materias/2014/10/05/comparecimento-diminui-maisuma-vez>. Acesso em 12 ago. 2015.

Brasil. Tribunal Superior Eleitoral. Informações e dados estatísticos sobre as eleições 2010 / elaboração Núcleo de Estatística da Assessoria de Gestão Estratégica. Brasília. Tribunal Superior Eleitoral, Secretaria de Gestão da Informação, 2010.

Brasil. Tribunal Superior Eleitoral. Dados estatísticos: eleições 2014. Brasília : Tribunal Superior Eleitoral, 2014.

BROCHADO, Mariá. Direito \& ética: a eticidade do fenômeno jurídico. São Paulo: Landy. 2006. CONSCIENTIZAÇÃO cívica, moral e política. 2008. Disponível em: $<$ http://editoriaisdodon.blogspot.com.br/2010/08/conscientizacao-civicamoral-epolitica.html>. Acesso em: 12 ago. 2015.

INGLEHART, Ronald F. La nuova partecipazione nelle societa postindustriali. Rivista Italiana di Scienza Politica, Bolonha, v. 17, n. 3, p. 403-445, dez. 1988.

KANT, Immanuel. Primeiros princípios da filosofia do Direito. In: WEFFORT, F. (Org.). Clássicos da Política (V.2). São Paulo: Ática, 1990.

KRIESI, Hanspeter; MULLER Lars (Ed.) Democracy: an ongoing challenge. Zurich: Lars Muller Publishers, 2013.

LATTMAN-WELTMAN, Fernando. Revista Compolítica, ago-dez2014, Vol. 4 Issue 2, p2757, 31p.

MANGABEIRA UNGER, Roberto. Democracia Realizada - a Alternativa Progressista. Tradução de Carlos Graieb, Marcio Grandchamp e Paulo César Castanheira. São Paulo: Boitempo Editorial, 1999. 
PEREIRA, Rodolfo Viana. Direito constitucional democrático: controle e participação como elementos fundantes e garantidores da constitucionalidade. Rio de Janeiro: Lumen Juris, 2008.

RACEGA DE BASTIANI, Ana Cristina. Reflexões sobre a crise da democracia representativa no Brasil pós Constituição Federal de 1988. Revista Thesis Juris. 3, 2, 257, Julho de 2014.

SILVA, José Afonso da. Curso de direito constitucional positivo. $9^{a}$ ed. São Paulo: Malheiros, 1994.

TOURAINE, Alain. O que é democracia. Tradução de Fernando Tomaz. Lisboa: Instituto Piaget, 1996. 